\title{
A Ten Year Review of Hydatidiform Mole in University of Calabar Teaching Hospital Nigeria
}

\author{
Iklaki Christopher Ubong ${ }^{1}$, Ago Boniface Uji ${ }^{1,}$, , Efiok Eyo Efiok ${ }^{1}$, Ebughe Godwin Abeng ${ }^{2}$, \\ Nnorom Felix ${ }^{1}$
}

${ }^{1}$ Department of Obstetrics and Gynaecology, University of Calabar Teaching Hospital, Calabar, Nigeria

${ }^{2}$ Department of pathology, University of Calabar Teaching Hospital, Calabar, Nigeria

\section{Email address:}

bonifaceago@yahoo.com (B.U Ago),chrisiklaki@yahoo.com(C.U Iklaki), efiokefiok@yahoo.com (E. E. Efiok), gobeng01@yahoo.com (G.A Ebughe), felrom3@yahoo.com (F. Nnorom)

\section{To cite this article:}

Iklaki Christopher Ubong, Ago Boniface Uji, Efiok Eyo Efiok, Ebughe Godwin Abeng, Nnorom Felix. Hydatidiform Mole in University of Calabar Teaching Hospital, Nigeria. A Ten Year Review. Journal of Gynecology and Obstetrics. Vol. 3, No. 4, 2015, pp. 88-91.

doi: $10.11648 /$ j.jgo.20150304.14

\begin{abstract}
Abstrct: Background: Hydatidiform mole is a cause of early trimester miscarriages which if not properly treated may lead to increasing severity of vaginal bleeding and maternal death. Aim: The aim of the study was to review the demographic characteristics of patients with hydatidiform mole, and the clinical outcome in the last decade. Subject, method and material: This was a retrospective review of cases of hydatidiform mole from $1^{\text {st }}$ of January 2004 to $31^{\text {st }}$ of December 2013 . The clinical data were retrieved from patients' folders and histologically confirmed cases were analyzed using EpiInfo7 and simple percentages. The total number of deliveries over the study period was obtained from the labour ward register. Results: There were 72 cases of hydatidiform mole giving a prevalence of 3.6 per 1000 deliveries. However only 68 folders contained results of histology. Women of age groups 35-39 years (48.5\%) and 15-19 years (26.5\%) were those predominantly affected. Vaginal bleeding $(85.3 \%)$, large for gestational age $(57.4 \%)$, anaemia $(57.4 \%)$, passage of vesicles $(55.9 \%)$ were the most common presentations. Pregnancy test was positive in all the cases, while ultrasononography aided diagnosis in $88.2 \%$ of the cases. Suction evacuation was done in all the cases. About $63 \%$ of patients had 1-3 months follow up, while $2.9 \%$ continued beyond 1 year. The case fatality was $1.47 \%$. However, 12 patients never came back to the hospital after evacuation. Conclusion: Molar pregnancy is a common cause of first trimester miscarriages and contributes to maternal morbidity and mortality in our Centre.
\end{abstract}

Keywords: Hydatidiform Mole, Presentation, Management, UCTH

\section{Introduction}

Hydatidiform mole refers to an abnormal pregnancy characterized by varying degrees of trophoblastic proliferation (both cytotrophoblast and syncytiotrophoblast) and vesicular swelling of placental villi associated with an absent or an abnormal fetus/embryo. ${ }^{1}$

There is a wide variation in the epidemiology of hydatidiform mole, but there are two clearly documented risk factors for an increased risk of molar pregnancy: the extremes of maternal age and a previous molar pregnancy. ${ }^{3} \mathrm{In}$ addition to age, a history of prior unsuccessful pregnancies for example, previous spontaneous abortion at least doubles the risk of molar pregnancy. ${ }^{4}$ Hydatidiform mole is either complete or partial. Cytogenetic studies demonstrate that complete moles are usually diploid, paternal in origin, and sex chromatin-positive - $46 \mathrm{XX}$ or $46 \mathrm{XY}$. They arise when an empty ovum (with an absent or inactivated nucleus) is fertilized by a haploid sperm that duplicates its chromosomes or by two haploid sperm. A partial mole, on the other hand, is triploid-69 XXY (70\%), $69 \mathrm{XXX}(27 \%)$, or $69 \mathrm{XYY}$ (3\%) - arising when an ovum with an active nucleus is fertilized by a duplicated sperm or two haploid sperm. Both of these processes result in a homozygous conceptus with a propensity for altered growth. ${ }^{5}$

Familial clusters of biparental complete hydatidiform moles associated with novel missense NLRP7 gene mutations on chromosome $19 \mathrm{q}$ have also been identified. ${ }^{1}$

Complete hydatidiform mole most commonly presents with vaginal bleeding, usually occurring at 6-16 weeks of gestation in $80-90 \%$ of cases. ${ }^{1}$ Patients with complete molar pregnancy are increasingly being diagnosed earlier in 
pregnancy and treated before they develop the classic clinical signs and symptoms as a result of widespread use of Ultrasonography and accurate tests for $\mathrm{hCG}^{1,2,5}$ More than $90 \%$ of patients with partial moles have symptoms of incomplete or missed abortion, and the diagnosis is usually made after histologic review of curettage specimens. ${ }^{1,2}$

Detailed history, physical examination, serial measurements of beta hCG levels, and ultrasonography, are necessary in the evaluation of the patients pre- and postevacuation. Suction evacuation and curettage is the preferred method of evacuation of a hydatidiform mole, independent of uterine size, for patients who wish to maintain their fertility. ${ }^{1,2,4,8}$

This study was conducted bearing in mind that a similar study had been done in this centre ten years ago. Has the picture changed?

\section{Methodology}

This was a retrospective study of cases of hydatidiform mole admitted to the gynaecology ward of the University of Calabar Teaching Hospital (UCTH) from $1^{\text {st }}$ of January 2004 to $31^{\text {st }}$ of December 2013. All women who were clinically diagnosed with hydatidiform mole were recorded but only folders with histological confirmation were selected for this review. It was a policy in the department for all cases of suspected molar pregnancy to have histologic confirmation. Thorough evaluation of the clinical notes was done. All cases of Gestational Trophoblastic Neoplasia(GTN) were excluded. Anaemia was defined as packed cell volume less than $30 \%$. Information regarding the demographic characteristics, clinical features, risk factors, treatment options, and followup were extracted and analyzed using Epi Info ${ }^{\mathrm{TM}} 7$ software from CDC Atlanta Georgia 2014, and simple percentages. Ethical consent was obtained to review the folders of the patients.

The number of folders with diagnosis of hydatidiform mole was 72, however only 68 of them (94.4\%) had histological confirmation. All the patients were treated by suction evacuation.

Total number of deliveries over the study period was obtained from the labour ward register.

\section{Results}

There were 19,918 deliveries over the period of study and 72 cases of hydatidiform mole, giving a prevalence of 1:277 or 3.6 per 1000 deliveries.

Table1 shows the gestational age at presentation. Most of the patients $(60.3 \%)$ presented in the first trimester, while $23.5 \%$ presented in the second trimester of pregnancy. The gestational age was unknown in $4.4 \%$ of the cases.

Table 2 shows the age of the patients at presentation with hydatidiform mole. Most of the patients $(48.5 \%)$ were aged $35-39$ followed by $26.5 \%$ aged $15-19$. Only about $11.8 \%$ were aged 20-29.
Table 3 shows the index pregnancy frequency. Most of the patients $(54.4 \%)$ were pregnant for the $5^{\text {th }}$ or more times while $14.7 \%$ of them were carrying their first pregnancies.

Table 4 shows that all the patients had a positive urine pregnancy test, while $88.2 \%$ had positive ultrasonographic findings. Most of the patients $(85.3 \%)$ presented with vaginal bleeding, while $55.9 \%$ presented with passage of vesicles. Pregnancy was large for date in $57.4 \%$ of the patients, but small for dates in $27.9 \%$. Anaemia was noted in $39(57.4 \%)$ of the patients. Of the 39 patients with anaemia, 30(76.9\%) received blood transfusion. Hyperemesis and preeclampsia were less common, occurring in $17.6 \%$ and $14.7 \%$ of the cases respectively.

Table 5 shows the follow-up history of the patients. Most of the patients (63\%) had follow up for 1-3 months only. 12 patients never came back after the evacuation, while 2 continued follow up beyond one year. In seven patients $(10.3 \%)$, the pregnancy test in dilution remained positive at $>1: 200$ dilutions and the vaginal bleeding persisted, four months after evacuation. The uterus also was bulky with positive sonographic findings for choriocarcinoma. Six of them were successfully treated with chemotherapy while one died of haemorrhagic shock before chemotherapy could be started. This patient presented late with severe vaginal bleeding and was admitted in shock. This gave a case fatality of $1.47 \%$.

Table 1. Gestational age at presentation with hydatidiform mole.

\begin{tabular}{llll}
\hline Gestationalage & Frequency & Percent & Cum. Percent \\
\hline 13 or less & 41 & $60.29 \%$ & $60.29 \%$ \\
$14-20$ & 16 & $23.53 \%$ & $83.82 \%$ \\
20 or more & 8 & $11.76 \%$ & $95.59 \%$ \\
unknown & 3 & $4.41 \%$ & $100.00 \%$ \\
Total & 68 & $100.00 \%$ & $100.00 \%$ \\
\hline
\end{tabular}

Table 2. Age of patients at presentation with hydatidiform mole.

\begin{tabular}{llll}
\hline Ageinyears & Frequency & Percent & Cum. Percent \\
\hline $15-19$ & 18 & $26.47 \%$ & $26.47 \%$ \\
$20-24$ & 3 & $4.41 \%$ & $30.88 \%$ \\
$25-29$ & 5 & $7.35 \%$ & $38.24 \%$ \\
$30-34$ & 6 & $8.82 \%$ & $47.06 \%$ \\
$35-39$ & 33 & $48.53 \%$ & $95.59 \%$ \\
40 or more & 3 & $4.41 \%$ & $100.00 \%$ \\
Total & 68 & $100.00 \%$ & $100.00 \%$ \\
\hline
\end{tabular}

Table 3. Gravidity of patients with hydatidiform mole.

\begin{tabular}{llll}
\hline Gravidity & Frequency & Percent & Cum. Percent \\
\hline 1 & 10 & $14.71 \%$ & $14.71 \%$ \\
2 & 5 & $7.35 \%$ & $22.06 \%$ \\
3 & 8 & $11.76 \%$ & $33.82 \%$ \\
4 & 8 & $11.76 \%$ & $45.59 \%$ \\
5 or more & 37 & $54.41 \%$ & $100.00 \%$ \\
Total & 68 & $100.00 \%$ & $100.00 \%$ \\
\hline
\end{tabular}


Table 4. Clinical features at presentation.

\begin{tabular}{lll}
\hline Clinical features & Frequency & Percentage (\%) \\
\hline Vaginal bleeding & 58 & 85.3 \\
Abdominal pain & 32 & 47.1 \\
Passage of vesicles & 38 & 55.9 \\
Hyperemesis & 12 & 17.6 \\
Anaemia & 39 & 57.4 \\
Large for dates & 39 & 57.4 \\
Small for dates & 19 & 27.9 \\
Pre-eclampsia & 10 & 14.7 \\
Positive pregnancy test(urine) & 68 & 100 \\
Positive ultrasound findings & 60 & 88.2 \\
Enlarged cystic ovaries & 13 & 19.1 \\
\hline
\end{tabular}

Table 5. Duration of follow up of patients with hydatidiform mole.

\begin{tabular}{llll}
\hline Duration of follow up & Frequency & Percent & Cum. Percent \\
\hline >1year & 2 & $2.94 \%$ & $2.94 \%$ \\
0-1 months & 20 & $30.88 \%$ & $33.82 \%$ \\
2-3 months & 22 & $32.35 \%$ & $66.18 \%$ \\
4-5 months & 8 & $11.76 \%$ & $77.94 \%$ \\
6months - 1year & 3 & $4.41 \%$ & $82.35 \%$ \\
lost to follow up & 12 & $17.65 \%$ & $100.00 \%$ \\
Total & 67 & $100.00 \%$ & $100.00 \%$ \\
\hline
\end{tabular}

\section{Discussion}

The prevalence of hydatidiform mole in this study was 1 in 277 or 3.6 per 1000 deliveries. This is lower than a similar study in this center reported ten years ago. ${ }^{5}$ In that study, the prevalence was 5.3 per 1000 deliveries. Previous studies in Nigeria have reported a range of 1.7 to 6 per 1000 deliveries. $^{6}$

The demographic characteristics and the clinical presentations of hydatidiform mole appear to have changed since the previous review. Women aged 35-39 and $15-19$ were more commonly affected. This pattern, however, is consistent with earlier studies where extremes of maternal age was a strong risk factor. ${ }^{3,7}$ Gravidity rather than parity was used in this study as a risk factor because parity does not affect the risk. ${ }^{8}$ A history of prior unsuccessful pregnancies increases the risk of gestational trophoblastic disease. For example, previous spontaneous abortion at least doubles the risk of molar pregnancy. ${ }^{4}$

About $14.7 \%$ hydatidiform mole occurred in primigravidas, this reduced in the secondagravidae to $7.4 \%$ and began to rise occurring in about $54.4 \%$ of patients who were pregnant for the $5^{\text {th }}$ time or above. Age may have been a strong risk factor here as the disease is commoner among teenagers and those 35-39 years old. It is also likely that some of these pregnancies which were aborted were abnormal trophoblastic proliferations, which increased their risk of subsequent gestational trophoblastic disease as gravidity increased. The gestational age at presentation also differed from the previous study. In this study, $60.3 \%$ of the patients presented in the first trimester as against $16.2 \%$ previously reported in this centre. First trimester presentation is commonly reported. ${ }^{9}$

Vaginal bleeding $(85.3 \%)$ was the commonest presentation. This agrees with previous studies where complete mole most commonly presents with vaginal bleeding, usually occurring at 6-16 weeks of gestation in $80-90 \%$ of cases. ${ }^{1}$ Anaemia, however, was the commonest presentation $(82.4 \%)$ in the previous study in our centre. It was present in $57.4 \%$ of patients in this study. The criteria for definition of anaemia in the previous study was (Haemoglobin less than 11 grams per deciliters), whereas in this study we used Packed Cell Volume less than $30 \%$. This difference may explain the lower incidence of anaemia in this study. Blood was grouped and cross-matched for all the patients prior to suction evacuation, only $30(44.1 \%)$ had blood transfusion. This represented $76.9 \%$ of patients who presented with anaemia.

The increased use of Ultrasound scan has significantly improved the diagnosis and promoted prompt uterine evacuation of molar pregnancy. ${ }^{10}$ Ultrasonography aided the diagnosis of hydatidiform mole in $88.2 \%$ of cases. Ultrasonography was commonly used in the evaluation of patients who presented with vaginal bleeding in early pregnancy, large or small for gestational age uteri, and abdominal pain. Ultrasonography plays a critical role in the diagnosis of both complete and partial mole, and it has virtually replaced all other means of preoperative diagnosis. ${ }^{10,11}$ It can be said that patients with complete molar pregnancy are increasingly being diagnosed earlier in pregnancy and treated before they develop the classic clinical signs and symptoms as a result of widespread use of Ultrasonography and accurate tests for hCG. ${ }^{1,2,9}$

Suction evacuation was the modality of management of the patients. This method reduces the risk of uterine perforation ,trophoblastic tissue embolization, and need for prophylactic chemotherapy. ${ }^{12}$ The use of suction evacuation in the treatment of these patients may have being responsible for non-documentation of complications such as uterine perforation and uterine infection. Medical induction of labour and hysterotomy are not recommended for molar evacuation. These methods increase maternal morbidity, such as blood loss, incomplete evacuation requiring dilation and curettage, and the requirement for caesarean delivery in subsequent pregnancies. They also increase trophoblastic dissemination and the development of postmolar GTN requiring chemotherapy. ${ }^{1,12}$

There was one case of death in this study (a case fatality of $1.47 \%$ ). This was due to hypovolemic shock from severe vaginal bleeding. The patient presented late and late. Findings were in keeping with metastatic choriocarcinoma.

Follow up of patients was a problem in this study. Only $2.9 \%$ of the patients had follow up beyond one year. Poor follow up has been a consistent finding in our setting ${ }^{5,6}$ Definitive follow-up requires serial serum quantitative hCG measurements every week until 3 consecutive tests show normal levels, after which hCG levels should be determined at monthly intervals for 6 consecutive normal levels. ${ }^{2}$ About $17.7 \%$ of the patients did not come back for follow up after the evacuation, while $63 \%$ were seen within 3 months. The cost of investigation may not be unconnected with their disappearance. We were unable to trace contraceptive 
methods in the folders. Patients for contraception are managed by the family planning unit, and separate folders are opened for them there.

One limitation of this study was that some patients used different names on new folders and are more likely to conceal information, making it difficult to actually record recurrence.

\section{Conclusion}

Molar pregnancy is common in Calabar and contributes to maternal morbidity and mortality in our centre. The use of ultrasonography in the evaluation of vaginal bleeding in early pregnancy, as well as histologic evaluation of products of conception are important in early diagnosis and treatment.

\section{References}

[1] Lurain JR. Gestational trophoblastic disease I: epidemiology, pathology, clinical presentation and diagnosis of gestational trophoblastic disease, and management of hydatidiform mole. Am J Obstet Gynecol 2010: 531-39.

[2] Ross S. Berkowitz, Donald P. Goldstein. In: Berek Jonathan S (ed).Berek \& Novak's Gynecology, 14th Edition. Lippincott Williams \& Wilkins 2007:2376-2405

[3] Philip Savage and Michael Seckl. Gestational Trophoblast Tumours. In: D. Keith Edmonds (ed). Dewhurst's Textbook of Obstetrics \& Gynaecology, eighth edition. Wiley-Blackwell 2012: 66-75
[4] Schorge, Schaffer, Halvorson, Hoffman, Bradshaw, Cunningham. Gestational trophoblastic disease. William's Gynecology.pdf, McGraw Hill access Medicine 2008:15091541

[5] Ekanem EI, Etuk SJ, Itam IH, Ekanem AD, Ekabua JE. Hydatidiform mole in Calabar, Nigeria: A ten -year review. Mary Slessor Journal of Medicine 2005;5:72-76

[6] Ocheke AN, Musa J, Uamai AO. Hydatidiform mole in Jos Nigeria. Niger Med J 2011; 52:223-6

[7] Berkowitz RS, Goldstein DS. Clinical practice: molar pregnancy. N Engl J Med 2009; 360:1639-45.

[8] Lisa Moore. Hydatidiform mole. Medscape. www.emedicine.medscape.com accessed February 12015.

[9] Paola Aghajanian. Gestational Trophoblastic Diseases. In: alan H DeCherney, Lauren Nathan, Neri Laufer, Ashley S Roman (eds). Current Diagnosis and Treatment Obstetrics and Gynecology, $11^{\text {th }}$ edition. McGraw Hill medical 2013:859-869.

[10] Santo-Ramos R, Forney JP, Schwarz BE. Sonographic findings and clinical correlations in molar pregnancy. Obstet Gynecol 1980;56:186-92

[11] Fine C, Bundy AL, Berkowitz RS, et al. Sonographic diagnosis of partial hydatidiform mole. Obstet Gynecol 1989;73:414-8

[12] Tidy JA, Gillespie AM, Bright N, et al. Gestational trophoblastic disease: A study of mode of evacuation and subsequent need for treatment with chemotherapy. Gynecol Oncol 2000;78: 309-12. 